\title{
BABY MASSAGE DAN BABY GYM UNTUK MENINGKATKAN DAYA TAHAN TUBUH BAYI Fitria Hayu Palupi ${ }^{1}$, Gipfel Remedina ${ }^{2}$ \\ 1,2Kebidanan (D3), STIKes Mitra Husada Karanganyar,Jawa Tengah, Indonesia e-mail: ${ }^{1}$ fitriahp45@gmail.com, ${ }^{2}$ gipfelremedina@gmail.com
}

\begin{abstract}
ABSTRAK Baby massage atau lebih dikenal dengan pijat bayi sebenarnya dapat dilakukan oleh orang tua. Namun sebagian besar orang tua merasa takut untuk melakukan pemijatan bayi sendiri. Orang tua juga masih jarang melakukan senam bayi (baby gym), sehingga mengandalkan bantuan orang lain untuk melakukan baby massage dan baby gym. Tujuan pengabdian masyarakat ini adalah agar orang tua mampu melakukan pemijatan pada bayi / balita serta melakukan stimulasi pada bayi melalui baby massage dan baby gym. Dengan melakukan baby gym dan baby massage dapat untuk meningkatkan daya tahan tubuh serta meningkatkan kecerdasan bayi agar dapat berkembang dengan optimal dengan melalui sentuhan (baby massage) dan gerakan senam bayi (baby gym). Pelaksanaan kegiatan dilaksanakan pada tanggal 23 Oktober 2020 menggunakan media zoom cloud meeting karena ini masih dalam masa pandemi Covid-19, maka dilakukan melalui virtual menggunakan zoom dan dilanjutkan evaluasi kegiatan pada tanggal 28 Januari 2021 yang bertempat di Balai Desa Madegondo dengan mengundang 3 orang ibu dan 2 kader kesehatan untuk pelaksanaan evaluasi dengan menerapkan protocol kesehatan yang ketat. Hasil evaluasi pre test nilai rata - rata pada ibu balita tentang pengetahuan baby gym adalah 95 (baik), sedangkan pelaksanaan baby massage adalah 70 (cukup). Nilai rata rata manfaat meningkatkan bounding dan daya tahan tubuh sebesar 100 (baik). Sedangkan nilai post test pelaksanaan baby gym sebesar 100 (baik), pelaksanaan baby massage 100 ( baik) dan manfaat meningkatkan bounding dan daya tahan tubuh sebesar 100 (baik). Simpulan kegiatan pengabdian masyarakat ini adalah menunjukkan adanya peningkatan pengetahuan dan ketrampilan ibu balita dalam melakukan baby gym dan baby massage sehingga dapat diterapkan dan diaplikasikan secara langsung.
\end{abstract}

KATA KUNCI Baby Massage; Baby gym; Daya tahan tubuh

ABSTRACT Baby massage or better known as baby massage can actually be done by parents. However, most of the parents feel afraid to do massage their babies themselves. Parents also rarely do baby gym, so they rely on the help of others to do baby massage and baby gym. The purpose of this community service is for parents to be able to massage babies / toddlers and stimulate babies through baby massage and baby gym. By doing a baby gym and baby massage, it can increase endurance and increase the intelligence of the baby so that it can develop optimally through touch (baby massage) and baby gym movements. The implementation of the activity was carried out on October 23, 2020 using the zoom cloud media meeting because this was still in the Covid-19 pandemic period, limitations in gathering the community, then it was done through virtual using zoom and continued with the evaluation of activities on January 28, 2021 
which took place at Madegondo Village Hall invited 3 mothers and 2 health cadres to carry out an evaluation by implementing strict health protocols. The results of the pre-test evaluation of the average value of mothers under five about the knowledge of the baby gym were 95 (good), while the implementation of baby massage was 70 (sufficient). The average value of benefits increases bounding and endurance by 100 (good). Meanwhile, the post-test score for the implementation of baby games was 100 (good), the implementation of baby massage was 100 (good) and the benefits of increasing bounding and endurance were 100 (good). The conclusion of this community service activity is to show an increase in the knowledge and skills of toddler mothers in doing baby gyms and baby massages so that they can be applied and applied directly.

KEYWORDS Baby Massage; Baby gym; Body endurance.

\section{Pendahuluan}

Baby massage merupakan teknik pemijatan yang dilakukan untuk bayi / balita secara lembut dan menggunakan gerakan - gerakan tertentu dengan tujuan untuk merangsang pengeluaran hormon endorphin yang menyebabkan bayi merasa nyaman dan relaks, sehingga akan meningkatkan daya tahan tubuh bayi karena merangsang meningkatnya aktivitas neurotransmiter neurotin. Peningkatan aktivitas neurotransmiter akan menyebabkan sel reseptor mengikat glucocoticoid yang menyebabkan penurunan hormon adrenalin, sehingga dapat meningkatkan imunoglobulin pada bayi/balita. . [1]. [2]. [3]. [4]. [6].

Baby massage atau lebih dikenal dengan pijat bayi sebenarnya dapat dilakukan oleh orang tua. Namun sebagian besar orang tua merasa takut untuk melakukan pemijatan bayi sendiri. Orang tua juga masih jarang melakukan senam bayi (baby gym), sehingga mengandalkan bantuan orang lain untuk melakukan baby massage dan baby gym. Padahal masa pandemi Covid-19 ini, pemijatan yang dilakukan oleh orang tua akan sangat baik sekali, sebab orang tua akan merasa aman dan nyaman untuk melakukan stimulasi pada bayi dengan baby massage dan baby gym untuk meningkatkan daya tahan tubuh serta meningkatkan kecerdasan bayi agar dapat berkembang dengan optimal dengan melalui sentuhan (baby massage) dan gerakan senam bayi (baby gym). Pemijatan yang dilakukan oleh orang tua, selain memberikan stimulus pada bayi / balita juga akan memberikan dampak positif dari bayi yaitu adanya kedekatan secara psikologis antara bayi dan orangtua. Dengan pemberian pendidikan kesehatan pada ibu bayi/balita maka ibu bayi / balita akan dapat menerapkan baby gym dan baby massage secara mandiri. [3]. [4]. [5]. [6].

Di Kabupaten Sukoharjo terdapat 3137 total positif Covid-19, dengan 2422 orang dinyatakan sembuh, 334 melakukan isolasi mandiri, 202 di rawat di Rumah Sakit, 179 orang meninggal. Berdasarkan kajian yang telah dilaksanakan, di Kecamatan Grogol Kabupaten Sukoharjo masih terdapat kasus aktif 37 orang dan suspek 114.

Dalam memutus mata rantai penyebaran virus Covid-19 di harapkan masyarakat mampu menerapkan hidup bersih dan sehat, serta dapat meningkatkan daya tahan tubuh serta imunitas [7].[8].[10]. Namun, karena orang tua pada umumnya belum memiliki kemampuan dan ketrampilan untuk melakukan baby massage dan baby gym, maka diperlukan pengetahuan dan ketrampilan dengan benar, serta melakukan dengan teratur, sehingga akan memberikan manfaat yang besar untuk meningkatkan daya tahan tubuh bayi/balita serta meningkatkan pertumbuhan dan perkembangan. Oleh karena itu penting kiranya ibu - ibu yang memiliki bayi/balita di Desa Madegondo Kecamatan grogol untuk dapat mengerti 
dan terampil melakukan baby massage dan baby gym agar daya tahan tubuh bayi meningkat.

Berdasarkan survey awal yang dilakukan pada beberapa ibu yang memiliki bayi/balita, ibu mengatakan bahwa belum mengetahui cara melakukan baby gym dan baby massage sendiri, sehingga pelaksanaanya mengundang dukun bayi atau melakukan pemijatan di tenaga kesehatan, namun pelaksanaannya tidak teratur.

Berdasarkan analisis masalah diatas, maka beberapa permasalahan yang dapat dirangkum agar orang tua mampu meningkatkan daya tahan tubuh anak melalui pemberian pemijatan pada bayi / balita adalah ibu bayi/balita belum berani untuk melakukan baby massage/baby gym karena merasa takut dan merasa tidak terampil dalam melakukan pemijatan, sehingga pemijatan bayi / balita dilakukan oleh dukun bayi atau tenaga kesehatan yang pelaksanaannya tidak teratur.

Dari beberapa permasalahan yang dihadapi oleh ibu bayi/balita di Desa Madegondo kecamatan Grogol Kabupaten Sukoharjo, maka target luaran dari pengabdian masyarakat ini adalah memberikan edukasi kepada ibu bayi/balita tentang pentingnya baby massage dan baby gym untuk meningkatkan daya tahan tubuh bayi/balita, meningkatkan ketrampilan ibu bayi/balita untuk dapat melakukan baby massage dan baby gym pada bayi/balita, meningkatkan hubungan psikologis antara ibu dan bayi melalui sentuhan baby massage dan baby gym.

Kegiatan pengabdian masyarakat ini penting dilaksanakan untuk memberikan edukasi dan ketrampilan pada ibu bayi/balita sehingga dapat melakukan baby massage dan baby gym ini secara mandiri dan teratur untuk meningkatkan daya tahan tubuh bayi balita pada masa pandemi Covid-19.

\section{Metode}

Kegiatan ini ditujukan bagi masyarakat di Desa Madegondo kecamatan grogol dengan jumlah peserta \pm 29 orang yang dilaksanakan pada tanggal 23 Oktober 2020 menggunakan media zoom cloud meeting karena ini masih dalam masa pandemi Covid-19, sehingga dilakukan melalui virtual menggunakan zoom dan dilanjutkan evaluasi kegiatan pada tanggal 28 Januari 2021 yang bertempat di Balai Desa Madegondo, dengan mengundang 3 orang perwakilan ibu balita dan 2 orang kader. Pelaksanaan knowlage transfer secara daring dilaksanakan untuk melakukan pendidikan kesehatan dan ketrampilan menggunakan vidoe pelaksanaan baby massage dan baby gym. Sehingga bisa digunakan sebagai pegangan dan dapat mengaplikasikan baby gym dan baby massage secara mendiri guna meningkatkan daya tahan dan imun tubuh pada bayi dan balita.

Adapun kegiatan pelaksanaan pengabdian masyarakat ini adalah sebagai berikut:

1) Penetapan peserta

Kegiatan pengabdian masyarakat ibu bertujuan agar ibu bayi/balita di Desa Madegondo Kecamatan Grogol Kabupaten Sukoharjo dapat terampil dalam melakukan baby massage dan baby gym, sehingga penetapan peserta pengabdian masyarakat ini adalah semua ibu yang memiliki bayi / balita di Desa Madegondo kecamatan Grogol Kabupaten Sukoharjo.

2) Perijinan

Sebelum pelaksanaan pengabdian masyarakat, maka tim pengabdian masyarakat melakukan koordinasi dengan bidan desa wilayah dan juga pemerintah (kepala Desa) Desa Madogondo Kecamatan Grogol Kabupaten Sukoharjo.

3) Persiapan kegiatan

Setelah dilakukan koordinasi dengan bidan wilayah Desa Madegondo Kecamatan grogol kabupaten Sukoharjo , maka tim pengabdian 
masyarakat melakukan koordinasi dengan para kader kesehatan diwilayah tersebut. Penilaian awal dilakukan dengan melakukan wawancara pada ibu Hesti Ramayani, AMd.Keb selaku bidan wilayah yaitu mengenai pelaksanaan kegiatan pengabdian masyarakat dengan tema baby massage dan baby gym yang dilakukan oleh ibu bayi/balita. Kemudian tim pengabdian menyusun proposal dan materi berupa video pembelajaran tentang baby massage dan baby gym serta menyiapkan sarana lainnya misalnya MMT dan juga leaflet.

4) Pelaksanaan

Pelaksanaan kegiatan dilakukan melalui daring dengan menggunakan aplikasi zoom cloud meeting karena masih dalam adaptasi baru masa pandemi Covid-19 yang dilaksanakan pada tanggal 23 Oktober 2020 mulai pukul $9.00-13.00$ WIB.

5) Evaluasi

Evaluasi dilaksanakan untuk mengetahui efektifitas pelaksanaan pengabdian masyarakat ini yaitu pada orang tua bayi / balita dapat melakukan baby massage dan baby gym dan dapat menerapkan dirumah minimal sehari 1 kali. Evaluasi dilakukan pada tanggal 28 Januari 2021 bertempat di Balai Desa Madegondo dengan dihadiri oleh perwakilan ibu yang memiliki bayi/balita.

\section{Hasil dan Pembahasan}

Pengabdian masyarakat ini dilakukan pada hari Jumat, 23 Oktober 2020 dengan menggunakan metode pelaksanaan kegiatan dilakukan secara daring melalui aplikasi zoom cloud meeting karena masih dalam adaptasi baru masa pandemi Covid-19 yang dilaksanakan pada tanggal 23 Oktober 2020 mulai pukul 9.00 sampai dengan 13.00 WIB. Jumlah peserta yang mengikuti penyuluhan ini adalah 29 peserta yang terdiri dari ibu yang memiliki bayi dan balita serta ibu hamil. Sedangkan evaluasi kegiatan dilakukan pada tanggal 28 Januari 2021 yang bertempat di balai desa Madegondo Kecamatan Grogol dengan dengan diwakili oleh ibu hamil, kader dan ibu yang memiliki bayi balita.

Dalam pengabdian masyarakat ini di mulai pukul 08.00 - 13.00, dimulai dengan registrasi peserta, pembukaan, pre test lalu di lanjutkan dengan pemberian materi terkait baby gym serta pemutaran video baby gym oleh Gipfel Remedina, SST, M.Keb. Sebelum masuk ke materi pembicara terlebih dahulu menanyakan apakah masyarakat sudah mengetahui cara meningkatkan imun atau daya tahan tubuh selama pandemi pada bayi dan balitanya. Rerata peserta menjawab belum mengerti cara meningkatkan daya tahan tubuh bayi dengan melakukan baby massage dan baby gym. Setelah itu menyampaikan terkait baby gym, manfaat baby gym, tumbuh kembang bayi, pemberian sugesti postif, serta langkah-langkah melakukan baby gym. Kemudian dilanjutkan dengan pemutaran video baby gym. Pembicara kedua oleh Fitria Hayu Palupi, SST, M.Kes menyampaikan materi terkait baby massage yaitu pengertian baby massage, umur dilakukan baby massage, manfaat baby massage pemberian sugesti postif serta langkah-langkah yang dilakukan dalam melakukan baby massage dan yang terakhir yaitu pemutaran video. Setelah materi selesai dilanjutkan dengan sesi pertanyaan oleh peserta dan diakhiri dengan post test

Adapun hasil evaluasi yang dilakukan melalui pengisian google form adalah sebagai berikut: 


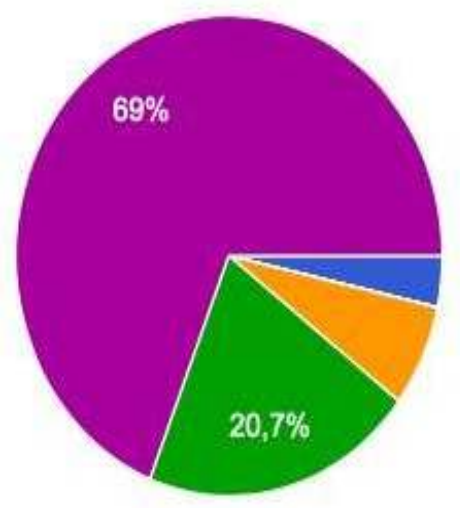

TIDAK SEKOLAH 1 orang ( $3,4 \%)$

SD

SMP 2 orang $(6,9 \%)$

SMA 6 orang $(20,7 \%)$

PERGURUAN TINGGI (S1/S2/S3) 20 orang ( $69 \%)$

\section{Diagram 1. Tingkat pendidikan Peserta}

Dari 29 peserta pengabdian masyarakat, berdasarkan tingkat pendidikan adalah sebagai berikut: peserta yang tidak memiliki ijazah 1 orang $(3,4 \%)$, telah menyelesaikan pendidikan setara SMP sebanyak 2 orang ( $6,9 \%)$, peserta yang telah menyelesaikan pendidikan SMA sebesar 6 orang $(20,7 \%)$ dan peserta yang telah menyelesaikan pendidikan tinggi sebesar 20 orang $(69 \%)$.

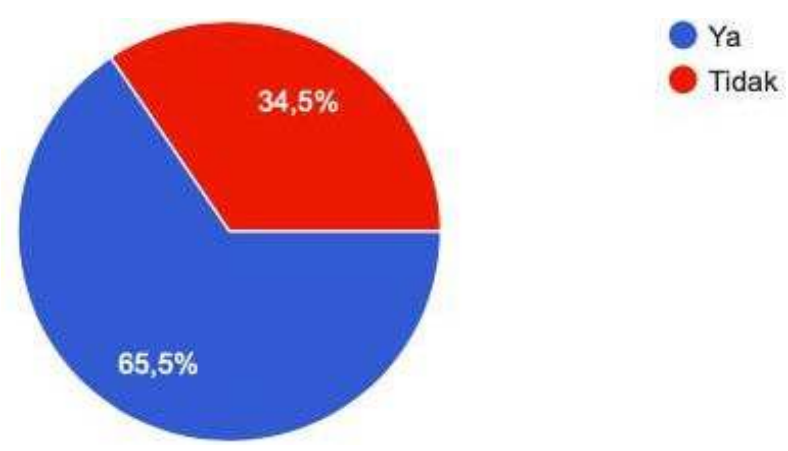

Diagram 2. Pengetahuan ibu tentang pelaksanaan baby gym dan baby massage

Evaluasi tentang pelaksanaan ibu dalam melakukan baby gym dan baby massage adalah sebagai berikut: terdapat $19 \mathrm{ibu}(65,5 \%)$ yang mengetahui bahwa bayi perlu dilakukan baby gym dan baby massage sehari 2 kali yaitu pagi dan sore, sedangkan sebanyak $10 \mathrm{ibu}(34,5 \%)$ yang belum mengetahu bahwa pelaksanaan baby gym dan baby massage dilaksanakan sehari 2 kali.

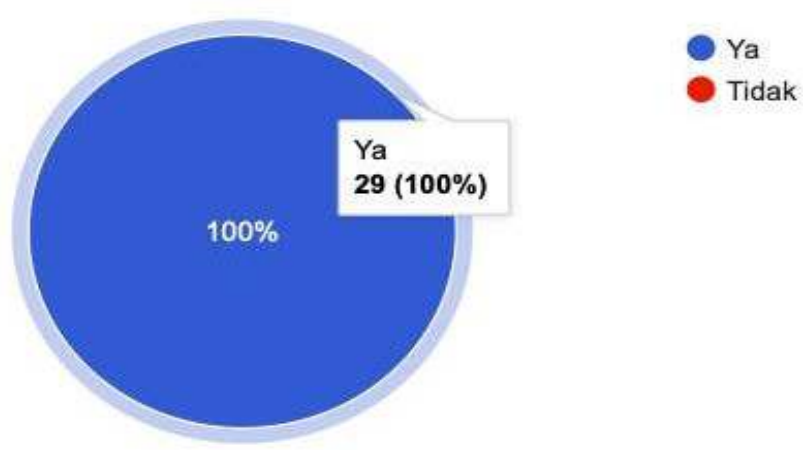

Diagram 3. Pengetahuan ibu tentang manfaat baby gym dan baby massage. 
Sebanyak $29 \mathrm{ibu}(100 \%)$ telah mengetahui manfaat dilakukan baby gym dan baby massage yaitu dapat meningkatkan bounding / ikatan kasih sayang antara ibu dengan bayi/balitanya serta dapat meningkatkan daya tahan tubuh bayi / balita apabila dilaksanakan secara teratur.

Tabel 1. Hasil pre tes dan post test

\begin{tabular}{|c|c|c|c|c|c|}
\hline No & Materi & $\begin{array}{l}\text { Nilai r } \\
\text { Test } \\
\text { Cukup }\end{array}$ & $\begin{array}{l}\text { ata- rata Pre } \\
\text { Baik }\end{array}$ & $\begin{array}{l}\text { Nilai ra } \\
\text { Test } \\
\text { Cukup }\end{array}$ & $\begin{array}{l}\text { ta - rata Post } \\
\text { Baik }\end{array}$ \\
\hline 1. & Pengetahuan & & & & \\
\hline & Pelaksanaan baby gym & - & 95 & - & 100 \\
\hline & $\begin{array}{l}\text { Pelaksanaan baby } \\
\text { massage }\end{array}$ & 70 & - & - & 100 \\
\hline 2 & Manfaat & & & & \\
\hline & Meningkatkan bounding & - & 100 & - & 100 \\
\hline & $\begin{array}{l}\text { Meningkatkan daya tahan } \\
\text { tubuh }\end{array}$ & - & 100 & - & 100 \\
\hline
\end{tabular}
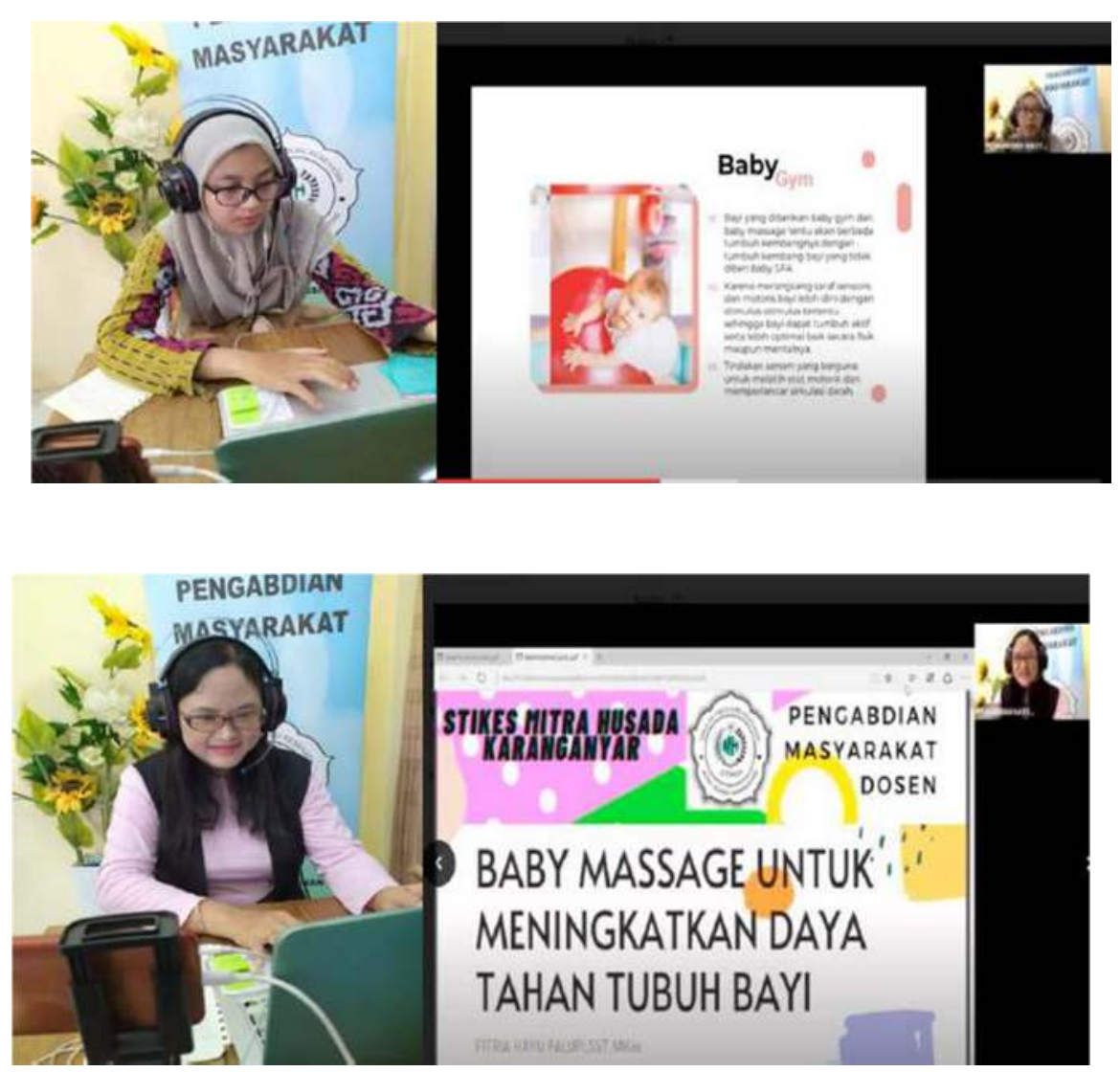

Gambar 1. Proses knowladge transfer Tahun 2020 


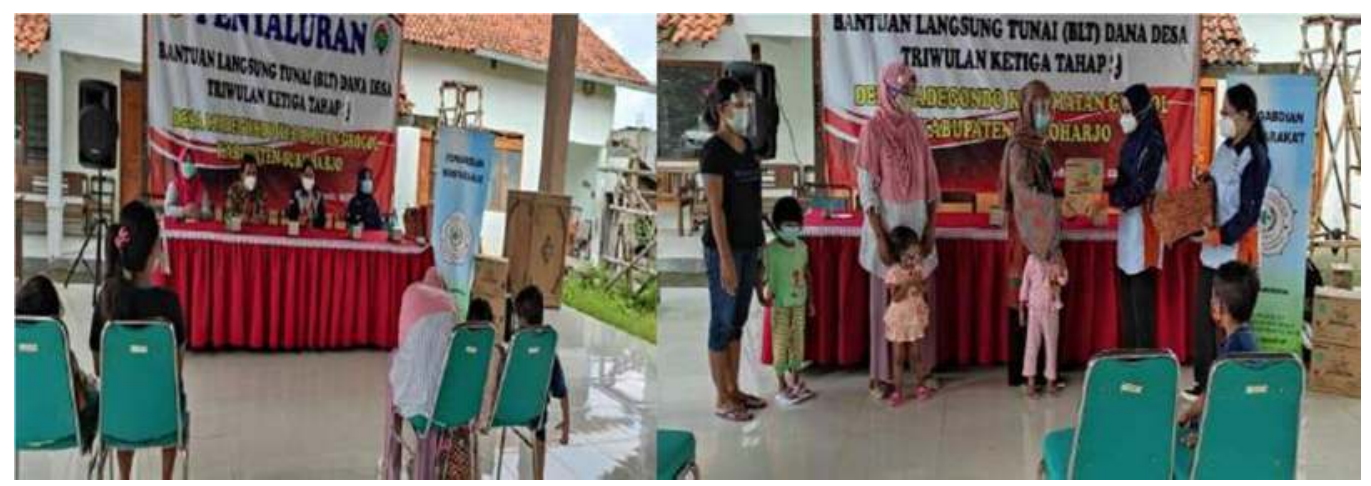

Gambar 2. Evaluasi kegiatan

Pentingnya dilakukan baby gym dan baby massage oleh pengasuh / orangtua dapat menurunkan penularan covid-19 karena telah membatasi bayi / anak berinteraksi dengan orang lain atau bepergian ke tempat lain

Selain penerapan protokol kesehatan seperti mencuci tangan, memakai masker menjaga jarak di sini orang tua wajib menjaga dan meningkatkan daya tahan tubuh bayi dan balitanya dengan cara meningkatkan imun yang dapat dilakukan dengan melakukan baby gym dan baby massage. [1]. [9].

Megawati, 2017 dalam penelitiannya menyebutkan bahwa pendidikan kesehatan merupakan suatu kegiatan atau usaha menyampaikan informasi kesehatan kepada masyarakat sehingga dapat meningkatkan pengetahuan tentang kesehatan yang lebih baik. Oleh karena itu pemberian informasi tentang baby gym dan baby massage bagi masyarakat terutama orang tua sangatlah penting, karena dengan begitu para orang tua dapat melakukan pada baby dan balita guna meningkatkan daya tahan tubuh dan imun . [2].

Baby gym dan baby massage merupakan perawatan pada bayi terutama usia 012 bulan karena pada masa itu bayi membutuhkan perawatan khusus untuk menjaga kesehatan untuk mengoptimalkan pertumbuhan dan perkembangan. Perawatan yang paling baik untuk bayi tersebut adalah dengan sentuhan dari terapis/ibu/pengasuh, dengan menggunakan teknik - teknik dan gerakan tertentu. [3]. [4].

Massage atau pijat merupakan terapi sentuh yang dapat diberikan kepada bayi agar memperoleh ketenangan. Pijatan yang dilakukan orang tua pada bayi secara lembut akan memiliki manfaat positif bagi bayi, yaitu meningkatkan kualitas tidur bayi sehingga dapat mengoptimalkan daya tahan tubuh bayi. Baby massage yang dilakukan oleh orang tua dengan menggunakan gerakan - gerakan tertentu dapat menjadi terapi dengan tujuan yaitu merangsang pengeluaran hormon endorphin sehingga membawa bayi nyaman dan rileks. Selain itu dapat meningkatkan daya tahan tubuh karena adanya aktivitas neurotransmiter neurotin sehingga kapasitas sel reseptor dapat mengikat glucocoticoid yang akan mengalai peningkatan. Peningkatan tersebut menyebabkan penurunan hormon adrenalin sehingga akan meningkatkan imunoglobulin. [4]. [5]. [6]. [10] Dalam melakukan baby gym dan baby massage maka orang tua / terapis perlu menciptakan suasana nyaman, sehingga perlu memastikan bayi siap untuk dilakukan pemijatan, Jangan memberikan pemijatan saat bayi mengantuk, tidur dan bayi keadaan lapar karena akan membuat bayi tidak nyaman dilakukan pemijatan. Selain itu perlu diperhatikan respon bayi saat dilakukan pemijatan, apabila bayi menangis keras maka lebih baik pemijatan dihentikan terlebih dahulu. Karena bisa jadi pada saat itu bayi belum siap dipijat, merasa bosan atau tidak nyaman.

Dengan memberikan stimulus pengetahuan dan ketrampilan tentang baby gym dan baby massage pada ibu balita, maka akan terjadi peningkatan pengetahuan ibu 
tentang baby gym dan baby massage sehingga menimbulkan kesadaran bagi ibu balita untuk melakukan baby gym dan baby massage secara teratur. [3].

Namun demikian peran kader kesehatan juga sangat diperlukan untuk senantiasa mendorong dan mengingatkan ibu untuk senantiasa melakukan protokol kesehatan dan menjaga daya tahan tubuh terutama pada balita. [7].

Upaya stimulasi perkembangan pada bayi melalui pijat bayi dapat dilakukan dengan cara memberikan edukasi kepada ibu bayi / balita dengan menggunakan metode demonstrasi. [12].

Karo 2019 berpendapat bahwa terjadi peningkatan pengetahuan ibu sehingga mereka bersemangat untuk melakukan gerakan senam sesuai dengan usia bayi mereka. Terjadi peningkatan keterampilan ibu sehingga mereka lebih percaya diri melakukan pijatan pada bayinya. Pendampingan dan pembinaan pada mitra memberikan dampak positif untuk lebih memaksimalkan pelayanan klinik dalam mengoptimalkan tumbuh kembang bayi. [13].

Hasil penelitian yang dilakukan oleh Hasanna 2019 menyebutkan bahwa terdapat perbedaan pada bayi yang dilakukan baby massage dan baby gym terhadap kemampuan telungkup pada bayi prematur. Penelitian serupa yang dilakukan oleh Yana yaitu terdapat peningkatan perkembangan bayi usia 6 bulan setelah dilakukan baby massage. [14]. [15].

\section{Kesimpulan}

Ada peningkatan pengetahuan dan ketrampilan ibu bayi dan balita untuk melakukan baby gym dan baby massage yang dilaksanakan 2 kali sehari guna meningkatkan daya tahan tubuh balita terutama pada masa pandemic Covid-19.

\section{Ucapan terima kasih}

Terima kasih kepada Ketua STIKes Mitra Husada Karanganyar dr. Dwi Surya Supriyana,M.Kes.Sp.AKp yang telah mendukung kegiatan pengabdian kepada masyarakat ini, kami juga mengucapkan terima kasih kepada Ana Winantiningsih, SST, M. Kes selaku Ketua LPPM STIKes Mitra Husada. Terima kasih kepada Kepala Desa Madegondo, Bidan Desa Madegondo, Ketua TIM Penggerak PKK Madegondo. yang telah berkenan memberikan kesempatan dan tempat pelaksanaan kegiatan pengabdian kepada masyarakat.

\section{Daftar Pustaka}

[1] Megawati and H. Akib, "Pengaruh kombinasi Pendidikan kesehatan dengan praktik pijat terhadap perilaku ibu dalam pemijatan bayi sendiri (usia 0-1 Tahun) di Desa Baratan Kecamatan Patrang Kabupaten Jember," J. Kesehat. dr.Soebandi, vol. 5, no. 1, 2017.

[2] D. S. Prasetyono, Buku Pintar Pijat Bayi. Jakarta: Buku Biru, 2013.

[3] Prasetyo, Teknik - teknik tepat memijat bayi sendiri panduan lengkap dan uraian kemanfaatannya. Yogyakarta: Diva Press, 2009.

[4] A. Putri, Pijat dan Senam Bayi dan Balita Panduan Praktis Memijat Bayi dan Balita. Yogyakarta: Briliant Offset, 2009.

[5] F. H. Palupi, Identifikasi peran kader kesehatan terhadap pengembangan desa siaga",. Prosiding, 2014.

[6] U. Roesli, Pedoman Pijat Bayi. Jakarta: Trubus Agriwidya, 2001.

[7] H. A. Rothan and S. N. Byrareddy, "The epidemiology and pathogenesis of coronavirus disease (COVID- 19) outbreak," J Autoimmun, vol. March, 2020, [Online]. Available: doi: 10.1016/j.jaut.2020.102433 . 
[8] A. Susilo et al., "Coronavirus Disease 2019: Tinjauan Literatur Terkini," $J$. Penyakit Dalam Indones., vol. 7, no. 1, p. 45, 2020, doi: 10.7454/jpdi.v7il.415.

[9] A. Syaukani, Pijat Senam dan Yoga Sehat untuk Bayi. Jakarta: Araska, 2015.

[10] C. Huang et al., "Clinical features of patients infected with 2019 novel coronavirus in Wuhan," Lancet, vol. 15, no. 395(10223), pp. 497-506, doi: doi: 10.1016/S0140-6736(20)30183-5.

[11] A. E. Gorbalenya, "Severe acute respiratory syndrome-related coronavirus The species and its viruses, a statement of the Coronavirus Study Group"," bioRxiv, doi: 10.1101/2020.02.07.937862.

[12] E. Revika and Y. Fitriana, "Edukasi stimulasi perkembangan melalui pijat bayi di Dusun Jati," JICE (The J. Innov. Community Empower., vol. Vol 2 Sept, no. 2, pp. 46-50, 2020.

[13] E. I. Karo and F. O. Kaban, "Optimalisasi tumbuh kembang bayi melalui edukasi terapi pijat bayi (baby Massage) dan senam bayi (baby gym) di klinik bersalin Kota Medan dan Kabupaten Deli Serdang Tahun 2018," J. Ris. Hesti Medan, vol. 4, no. 1.

[14] Hasianna, A. Meidian, and M. Samekto, Perbedaan pengaruh baby massage dan baby gym terhadap perkembangan kemampuan telungkup pada bayi lahir premature di Klinik Anakku. 2019.

[15] Y. E. Mildiana, "pengaruh baby gym terhadap peningkatan perkembangan bayi usia 6 bulan (Studi di Desa Kayangan Kecamatan Diwek Kabupaten Jombang),"," Midwifery J. STIKes Insa. Cendekia Med. Jombang, vol. 17, no. 1, pp. 94-99, 2019. 